\title{
Fernando Pessoa e as diferentes leituras de sua vida e obra
}

\author{
Fernando Pessoa and the different readings of his life and work
}

\section{Pedro Teixeira da Mota}

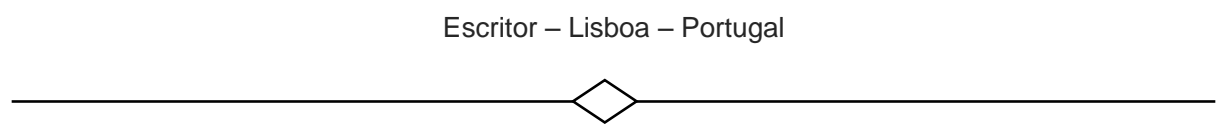

Resumo: A vida e obra de Fernando Pessoa podem ser lidas e interpretadas de diferentes modos ou níveis. Entre as linhas de força dela destaca-se a do ocultismo ou esoterismo, patente desde cedo nos seus escritos, leituras e investigações. Devido à sua subtileza e natureza simbólica em que se expressa, o Esoterismo não é facilmente aceite ou compreendido por muitos comentadores menos sensíveis ou interessados em tais dimensões. Esta compreensão torna-se ainda mais difícil porque durante a sua vida Fernando Pessoa entrou em tantas investigações, criou tantas afiliações ou projectos, e porque muitos dos seus textos póstumos esotéricos não estavam datados, prestando-se assim a ser vistos como contraditórias. Torna-se então muito importante compreender as suas fontes de conhecimento culto, quem foram os autores que ele leu mais e anotou e que quais os temas e níveis mais investigados. Hoje é possível, com muitos mais inéditos publicados e a sua obra mais contextualizada pelos trabalhos milhares de investigadores, termos uma leitura e compreensão mais profunda do seu vastíssimo conhecimento, desde a poesia à sociologia, da astrologia e simbolismo às ordens esotéricas e iniciação e uma leitura mais acertada do seu caminho hermenêutico espiritual e do seu lugar na Tradição Literária e Espiritual Portuguesa, que delinearemos também rapidamente desde o galaico-português até ao Modernismo do século XX, partilhando ainda alguns textos esotéricos e autobiográficos mais significativos. Toda esta demanda oculta, manifestada hoje para nós nos seus múltiplos textos, anotações ou ensaios inéditos em vida, culminarão nos seus poemas esotéricos publicados em revistas, na sua obra prima a Mensagem, na defesa das Associações Secretas, e finalmente na sua iniciação, de que algumas indicações são dadas nas notas autobiográficas ou testamentos finais, dos quais partilhamos partes, ao que acrescentaremos alguns dos seus mais relevantes textos espirituais.

Palavras-chave: Leituras da vida e obra. Influências ocultistas. Evolução e iniciação.

\begin{abstract}
Fernando Pessoa life and work, its biographies, perspectives or readings. Lines of force of his path: the innate genius and Occultism and Initiation. Difficulty of identifying and understanding his esoteric writings and notes unpublished in life, undated and so prone to be seen as contradictory. His sources of occultism, who were the authors more read and annotated, what subjects and levels he investigated deeper and related more, with whom may he have discussed, what were his main aspirations and projects. His place or contextualization in the Portuguese Spiritual and Literary Traditions. All his Occult search, unpublished in life in great part, manifested to us today in his multiple poems and texts, culminated in life in his genial work, "Orpheu" and the heteronyms being the most remarkable, in his esoteric poems published in reviews, in his most accomplished poem Mensagem, in his defense of freedom of Secret Associations and on his inner attainments and initiation, from which some hints were given in his autobiographical notes, especially the last one, some parts beings reproduced here, with extracts of other relevant texts.
\end{abstract}

Keywords: Metaphor. Readings of his life and work. Occult influences. Evolution and initation. 
A vida e obra de Fernando Pessoa, desde 30 Novembro de 1935, a data em que morreu, até aos nossos dias, apesar de ter sido lida ou interpretada de tantos modos, talvez mais complementares e esclarecedores se houvesse suficiente amplidão para os acolher ou confrontar imparcial, grupal e harmoniosamente, é ainda um desafio não só quanto a certos aspectos biográficos como quanto à evolução das suas crenças, ideias e realizações, especialmente as da sua espiritualidade, ocultismo e iniciação, cujos textos, pela subtileza dos temas e símbolos e os diferentes níveis de leitura ou interpretação, não são facilmente compreendidos.

Literariamente não é difícil constatar que o poeta cultivou desde cedo várias correntes, tais como o simbolismo, o paulismo, o intersecionismo, o sensacionismo, o futurismo, o neo-classicismo, o modernismo, bem visíveis nos seus três heterónimos e nele o ortónimo, certamente com várias facetas ou fontes, desde o que pensa, sente ou se deprime até ao simbolista e ocultista, e desde o nacionalista ao cosmopolita e universalista.

Assim, poética, literária, sociológica, estética e ideologicamente a obra de Fernando Pessoa é compreensível ainda que, ao escrever por vezes contraditoriamente e cultivando o paradoxo e a ironia, escapará sempre a uma compreensão plena ou a uma caracterização ou explicação definitiva, configurando-se antes como obra aberta, tanto mais que ainda há textos inéditos com valor ou significativos e que o poeta não datou muitos dos seus escritos, podendo-se assim tomar como uma posição madura ou final o que é uma simples opinião ou expressão mais juvenil. Quanto aos seus textos autobiográficos, entre o que é mistificação e o que é verdadeiro ou real, também nem sempre é fácil discernir.

É natural então que as sucessivas leituras da obra de Fernando Pessoa, ou as biografias, da qual a de João Gaspar Simões foi a primeira e a mais conseguida, seguindo-se outras como a de António Quadros, tenham de ser lidas nas suas contextualizações, ao provirem de olhares com limitações ou preconceitos. Claro que hoje em dia estando já publicados a maior parte dos seus textos inéditos, e grande parte da sua obra muito investigada e contextualizada por milhares de pessoanos, sabe-se muito mais e os últimos a escrever, como Richard Zennit e outros, podem-no realizar bastante melhor, embora as limitações, sobretudo de sensibilidade e conhecimento espiritual em relação ao caminho interior, esotérico e iniciático de Fernando Pessoa continuem visíveis.

De facto, quando nos interrogamos sobre o sentido e valor do seu percurso no ocultismo, no esoterismo, no hermetismo, na mística, na gnose, na alquimia espiritual e na iniciação deparamo-nos com dificuldades não só pela subtileza do abrangido como pela multiplicidade por vezes contraditória de escritos e fragmentos (calcularei cerca de 700, embora permeando muitos mais, e excluindo-se os de Astrologia) e pelas poucas confissões e textos definitivos e datados, ainda que a carta à tia Anica de Junho de 1916, a carta a Casais Monteiro, de Janeiro de 1935 e a sua nota biográfica de Março de 1935 sejam bastante clarificadoras, as últimas duas quase testamentos, certamente com nuances mistéricas.

Acresce que os seus amigos, e sobretudo os pessoanos que virão a comentá-lo, em geral sabiam pouco de tais aspectos espirituais ou herméticos e acabaram, pela insuficiência de conhecimentos e vivências e de acesso ao espólio inédito, ou por desinteresse ou menosprezo, por não valorizar ou compreender a trajectória evolutiva ou as compreensões mais valiosas nestes campos, embora ensaístas como Dalila Pereira da Costa, António Quadros, Yvette Centeno, Hakira Osakabe e Maria Helena Nery Garcez, tivessem bastante mais abertura a tais vivências e as espelhassem nas suas obras ou comentários

Em 1988, 100 anos depois do seu nascimento, publiquei nas Edições Manuel Lencastre um primeiro livro intitulado Moral, Regras de Vida e Condições de Iniciação, seguindo-se mais três, nos quais, apoiado em vários textos, tentei partilhar e interpretar o que me pareceu serem algumas das compreensões e vivências mais importantes do fio da vida ocultista e espiritual de Fernando Pessoa, precocemente 
cortado em Novembro de 1935, aos 47 anos, e que perduram como clarificadoras dos níveis trabalhados e alcançados na sua evolução, os quais exporemos resumidamente.

Ao realizarmos este seminário no Brasil, faremos agora uma breve contextualização da inserção de Fernando Pessoa na tradição cultural de língua Portuguesa que, como sabemos, teve a sua origem no Galaico-Português. Tal idioma, falado no extremo nordeste da Península Ibérica e fruto da passagem de diversos povos, em especial os Romanos, começa a emergir por escrito nos séculos XII e XIII e será difundido literariamente seja nas Cantigas de S. Maria, de Afonso X de Castela, seja nas famosas Cantigas de Amigo, tão femininas, nas quais se destacará como seu cultor o rei D. Dinis, caracterizado pelo dito popular que "fez tudo quanto quis" e que Fernando Pessoa valorizou não só na Mensagem, como em alguns escritos, pois fora ele em Portugal quem permitira que a corrente ou tradição Templária não fosse destruída e passasse para a Ordem de Cristo, sob a égide da qual se fariam uma centena de anos depois os Descobrimentos, quando era seu governador e regedor o Infante D. Henrique.

Este último, outro dos heróis ou símbolos vivos da Mensagem, foi também trabalhado por Fernando Pessoa nos seus textos acerca de uma ressurgência da Ordem Templária ou de Cristo em Portugal, que ele desejava no seu tempo (ou noutro...), e para a qual escolhera como lema a divisa do Infante: Talent de bien faire.

Se Luís de Camões será o poeta que imortalizará o feito de Vasco da Gama e dos nautas que abriram o caminho marítimo da Europa para o Oriente e o começo da globalidade planetária, nos Lusíadas, sendo ainda as suas Rimas, plenas de amor neo-platónico e cristão, de grande valor e sentimento, outros escritores nessa época áurea de quinhentos e seiscentos se destacaram, tal como Gil Vicente, Sá de Miranda, Bernardim Ribeiro, Jorge de Montemor, Jorge Ferreira de Vasconcelos, D. Francisco Manuel de Melo, D. Manuel de Portugal e outros, embora Fernando Pessoa não os valorizasse muito.

Importante na filiação literária e espiritual de Fernando Pessoa, que se profetizou até num artigo da importante revista Águia em 1912 como um SuperCamões, será o padre António Vieira (1608-1697), pregador de grande fôlego, missionário jesuíta muitos anos no Brasil, diplomata, e um dos melhores escritores da língua portuguesa, algo que afirmará várias vezes, valorizando a sua capacidade profética vaticinadora de um Império, então cristão e que, na última versão já mais cultural de Fernando Pessoa, seria o da Língua Portuguesa e da unidade das Religiões. Na Mensagem, nos Avisos que antecedem os Tempos finais, o P. António Vieira, "Imperador da língua Portuguesa" estará presente, como uma das três vozes futurantes, antecedido pelo sapateiro e visionário Bandarra, e seguido ou culminado pelo próprio Fernando Pessoa, o qual aspira a um ungimento verdadeiro por Deus que faça desaparecer o mal.

No séc. XIX, com as invasões francesas e as guerras entre Liberais e Absolutistas, e no qual surge a Independência do Brasil e a emergência da burguesia e da democracia eleitoral, literariamente quem prevalece após o classicismo e o barroco é escola Romântica, desenvolvida até por alguns lutadores liberais, tais como Alexandre Herculano e Almeida Garrett. Na segunda metade do século, um conjunto de escritores formado em Coimbra lançará um ataque às tendências balofas do Romantismo, arvorando a bandeira da liberdade, da verdade, da justiça, do socialismo, do amor, da ironia crítica e do realismo, com Antero de Quental, à cabeça, Eça de Queiroz, Guilherme de Azevedo, Teófilo Braga, Jaime Magalhães de Lima, Oliveira Martins e outros. Para Fernando Pessoa é com Antero de Quental que emerge a poesia moderna portuguesa, apontando como outros dois autores valiosos Cesário Verde e Camilo Pessanha e, de certo modo, ainda que bem menos, António Nobre, Teixeira de Pascoaes, João de Deus e Guerra Junqueiro.

É neste panorama ou contexto literário que Fernando Pessoa se encontrará, ao nascer em Lisboa em 1888, e ao revelar-se logo um génio 
precoce de inteligência e escrita, bem apoiado em casa por um pai crítico de música e teatro e uma mãe leitora, e depois, na escola, já na África do Sul, para onde vai em 1896, por morte do pai e segundo casamento da mãe, e onde ficará até Agosto de 1905, com uma vinda de um ano a Lisboa e aos Açores entre 1901 e 1902.

Fernando Pessoa completará os cinco anos do ensino primário em três, numa escola do convento de freiras irlandesas, e em 1899 entrava no Durban High School, onde conheceu o mestre escola Nicolas, um bom latinista que o reconhecerá e estimulará na leitura de boas obras inglesas que o influenciarão: Shakespeare, Milton, Charles Dickens, Chaucer, Shelley, Tennyson, Carlyle, Edgar Allan Poe e Walt Whitman serão lidos então mas também já certas obras de carácter mais esotérico, tais como presumivelmente as de Henry Drumond (1903), esoterismo aliás já muito presente em Shakespeare e Milton.

Já adquirida depois de 1907, mas referida por ele em 1915 como lida há muito tempo e que impressionara fortemente está, de Hargrave Jennings, The Rosicrucians: Their Rites and Mysteries, na edição de 1907, curiosamente um inspirador de ordens secretas ou iniciáticas que mais tarde Fernando Pessoa estudará e que por fim conhecerá até por contacto pessoal, ao encontrar-se com Alesteir Crowley, o famoso mago e ocultista que veio a Lisboa em Setembro de 1930 durante três semanas para o conhecer e de algum modo iniciar, para além de outros objectivos que deram azo a uma mistificada tentativa de suicídio, aproveitada por Fernando Pessoa para artigos de revistas e um romance policial.

Nesta relação com Aleister Crowley houve como que um fechar do anel ou círculo e até da unidade luso-britânica que Fernando Pessoa trilhara, pois traçara alguns círculos mágicos com seres e assuntos desde 1907, conforme o poema The Circle, onde afirmava já um dos leif motivs do seu percurso: todo o seu pensamento só lhe dava ou se resumia a símbolo e analogia. Mais tarde, aprofundando os seus conhecimentos ocultos, escreverá sobre o valor dos círculos e laços mágicos, ou as egrégoras de afinidades, e nos seus últimos poemas ocultistas confessará a sua incapacidade da evocação mágica (no Último Sortilégio, afirmado por ele como um mero poema acerca da magia ao contrário do Pan, de Aleister Crowley, que traduzira e veio a ser publicado na revista Presença em 1931), e a supremacia da mística sobre a magia, no ciclo de poemas intitulados Isaac Luria e Jesus de Nazaré, por mim publicados pela $1^{\text {a }}$ vez em Poesia Profética, Mágica e Espiritual, 1989.

Para a formação da sua capacidade literária mais esotérica houve então essas leituras iniciais estimulantes e de obras bem escritas, outras realizadas na Biblioteca Nacional (de que há listas em diários ou anotações em papéis), outras ainda pelas encomendas que fazia na Livraria Inglesa e das quais há registos dos pedidos e chegadas de obras, de autores como Ramacharaka ou Papus, enriquecendo assim a sua biblioteca, hoje na casa museu Fernando Pessoa, com os seus cerca de 1279 livros, alguns dos primevos provindos da África de Sul, até recebidos de prémios escolares, e assinados com os primeiros semi-heterónimos, tais como Charles Robert Anon (o $1^{\circ}$ a ser criado por volta de 1904), Alexander Search e Thomas Cross, revelando a proximidade íntima e ciosa ou amorosa com alguns livros, ou o culto da leitura que sempre o caracterizou (ainda que, infelizmente, em 1932, pouco antes de morrer the tenham recusado a candidatura a bibliotecário, em Cascais), formadora de uma ampla base de cultura geral e da qual brotaria a síntese criadora ou a pomba da inspiração, como nos deixou escrito nos seus ensaios sobre o Génio e a Intuição, e que na época mais juvenil brilhava já quase inatamente em jornais manuscritos e poemas, onde a sua fina inteligência analítica e imaginativa se manifestava tão precocemente.

Das leituras e investigações, das quais resultaram numerosos escritos e projectos, realçaremos na época inicial as leituras filosóficas de autores ateus ou agnósticos, nomeadamente de Max Nordau e Nieztche, ou de críticos do Cristianismo e de Jesus, tal como J. M. Robertson, Alfred Loisy, 
Binnet-Sanglet e a sua La Folie de Jesus, esta intensamente comentada, e que fazem parte de uma busca de princípios morais e de ordem para além do Cristianismo (ou Cristismo, como chamou também), o que vai resultar em breve numa valorização crescente do fundo greco-romano da nossa civilização e, consequentemente do regresso ao Paganismo, com algumas teorizações sobre o Neopaganismo ou o Paganismo Transcendental, assinadas por semiheterónimos, tais como António Mora e Raphael Baldaya. De referir ainda as leituras das simbolistas franceses, de Mallarmé e Baudelaire a Rimbaud e Nerval.

Simultaneamente vai-se desenvolvendo a busca Oculta e uma das muitas razões que deu quanto à sua atracção por tais conhecimentos foi a seguinte: "O ocultismo, porém, como a todas as religiões transcende e excede, excede e transcende cada uma de per si através dela mesma. Não lhe diminui os símbolos, as lendas e os ritos, senão que os eleva, interpretando-os, para fora da materialidade que lhes impôs o baixo espírito, crédulo que não crente, da maioria dos seus fiéis". (BNP/E3, 54-55). Através do Ocultismo e dos ensinamentos das Ordens secretas ou iniciáticas Fernando Pessoa procurava aprofundar a sua compreensão dos grandes mistérios da Vida e que diziam respeito à Divindade, aos diversos planos de manifestação e aos seres e energias subtis ou ocultas que os constituíam, à capacidade de o ser humano de saber despertar e utilizar tais forças e capacidades, fortalecendo-o num autoconhecimento da sobrevivência do espírito face à morte.

Dos autores mais importantes ocultistas ou esoteristas lidos directa ou indirectamente e citados, testemunhando o seu interesse, destaquemos dos mais antigos Hermes Trismegisto, Apuleio, Juliano Apóstata, Christian Rosenkreutz, Jakob Boëhme, Robert Fludd, Claude de Saint-Martin e, já mais modernos, Joseph Grasset, com o seu L' Occultisme hier et aujourd'hui, le merveilleux prescientifique, 1908, ainda assinado no exemplar pelo heterónimo Alexander Search, ou Eusèbe Salverte Des Sciences Occultes, de 1856. E Alan Leo, Papus, Eliphas Levy,
St. Yves de Alveydre, Blavatsky, Franz Hartmann, Rudolf Steiner, Arthur Edward Waite, Oswald Wirth, A. Siouville, Aleister Crowley, Manly P. Hall, Claude Bragnon, etc.

Da tradição Portuguesa, Fernando Pessoa leu obras de Bandarra e P. António Vieira (dois seres messiânicos que o apoiaram nas suas idealizações do Quinto Império universal da língua, da cultura e do espírito), Anselmo Caetano de Munhoz, Martins de Pascoal, José Anastácio Cunha, Miguel Dias ou mesmo Antero de Quental, de quem traduzira em jovem muitos dos sonetos para inglês $e$ provavelmente a pioneira obra teosófica (1889) do Visconde de Figanière, Estudos Esotéricos: Mundo, Submundo e Supramundo. Dos contemporâneos destacaremos Sampaio Bruno, Gomes Leal, João Antunes, Martins Velho, Augusto Gomes Ferreira, César Porto, Synesius, Mario Saa, Lusitanus (o médico madeirense Abel de Sousa Vasconcelos).

Entre os autores mais importantes que 0 ajudaram a aprofundar o Cristianismo e frequentemente a distanciar-se, ou pelo menos a aprofundá-lo, mencionemos Alfred Loisy, Ceaser Morgan, Walter Richard Cassel e a sua Supernatural Religion: an inquiry into the reality of divine revelation, John M. Robertson, com dez obras ainda hoje na sua biblioteca, Frederic Conybeare e Henry Drumond, este com a sua Natural Law in the Spiritual World, mais de uma vez citado.

Entre as pessoas com quem se relacionou e o influenciaram realçaremos o irmão do padrasto, o general Henrique Rosa, que considera no diário juvenil um grande filósofo pessimista com uma mente e um conhecimento científico enormes, e a tia Anica, aberta ao espiritismo. Nos seus encontros e tertúlias animadas em cafés lisboetas, por onde passava várias vezes ao dia por entre os seus trabalhos de tradutor e escritor comercial, destacam-se os Martinhos e a Brasileira, o Montanha e onde Fernando Pessoa dialogava com muitos escritores e artistas, nomeadamente com Almada Negreiros (que desenvolverá bastante a geometria sagrada), Armando Cortes-Rodrigues, João Correia de Oliveira, Carlos Amaro, Augusto de Santa-Rita, Teixeira de 
Pascoaes e Leonardo Coimbra (acerca de quem há, por exemplo, uma anotação muito elogiosas no diário de Novembro de 1915 e noutros apontamento, sendo os três últimos que provavelmente o terão convidado a participar na revista Águia, aquela que sucedera à Revista de Portugal (1889-192), de Eça de Queiroz, de Antero e de Oliveira Martins, e ambas elogiadas por Fernando Pessoa.

Serão dois artigos, em duas partes, de análise crítica, A Nova Poesia Portuguesa Sociologicamente considerada, e A Nova Poesia Portuguesa no seu aspecto Psicológico, publicados nos nº 4 e 5, 9 e 11 de 1912, em sintonia com as posições mais espirituais e futurantes dos membros e artigos dessa revista do movimento Renascença Portuguesa, nascido logo após a proclamação da República, no Porto, e que concluíram com o vaticínio da vinda de um "super-Camões", ele mesmo, algo que na realidade se cumprirá, como os nossos dias o comprovam e já na altura a geração literária seguinte reconheceu, aglutinada na revista de Coimbra Presença (1927-1940), dirigida por Branquinho da Fonseca, José Régio e João Gaspar Simões, sendo este crítico de literatura o primeiro a fazer-lhe 0 reconhecimento devoto ou admirativo público, o qual alegrou bastante o poeta, quem sabe, tal como algumas conversas amigas e o surgimento da revista Orpheu, dos momentos mais gratos da sua vida...

A não publicação na Águia do seu drama estático O Marinheiro contribui para o corte com 0 Porto e a revista Águia e a passagem para o epicentro lisboeta, sensacionista, modernista e futurista, com Mário de Sá-Carneiro (que também colaborara com três contos na Águia), Luís de Montalvor, Alfredo Guisado, Santa-Rita pintor, António Botto, Almada Negreiros, Adolfo Castané, João Correia de Oliveira, Raul Leal, Augusto Ferreira Gomes e alguns outros, revolucionando o meio cultural fortissimamente com a revista Orpheu, originando vários artigos trocistas dos jornais e uma certa polémica com o escritor Júlio Dantas e outros, tal e qual acontecera com o patriarca Castilho face à juvenil escola Coimbrã, liderada por Antero de Quental e Germano Meireles, no que foi conhecido como a Questão Coimbra e que deu origem a tantos opúsculos polémicos.

Antero será uma constante referência de Fernando Pessoa, que traduziu mesmo para o inglês muitos dos sonetos, escrevendo num diário em 1908 que o seu único conforto na época era lê-lo e que se considerava um irmão em espírito, compreendendo bem o seu sofrimento pela pátria, ecoando já nestas expressões o grande patriotismo ou nacionalismo místico de Fernando Pessoa, tão desiludido da vida política portuguesa como o fora Antero de Quental, este confessando-o bem no seu último ano de vida, após a sua intervenção política inútil como presidente da Liga Patriótica do Norte, criada pela movimentação dos estudantes nortenhos contra o opressivo Ultimatum inglês de 1890.

1914 e 1915, o ano da revista Orpheu, são os anos chave do entusiasmo e criatividade de Fernando Pessoa, surgindo a criação genial dos três heterónimos, o primeiro no dia triunfal de 8/3/1914, o mestre da simplicidade Alberto Caeiro, seguindo-se o greco-romano ou neo-clássico e disciplinado horaciano Ricardo Reis e, por fim, o sensacionista ou emotivo futurista supra-personalidades Álvaro de Campos, que contudo será o primeiro a revelar-se ao público, na Ode Triunfal no Orpheu 1, os dois primeiros tendo de esperar pela revista de arte Athena, de 1924-25, para saírem a lume.

A revista congeminada e gerada por Fernando Pessoa e Mário de Sá Carneiro (o seu maior amigo, e já antes projectada com o nome de Lusitânia, e depois de Europa) nasceu como uma parceria lusobrasileira, pois Luís de Montalvor trouxera o nome da ideia e da revista do Brasil, além da colaboração dos "jovens poetas brasileiros" Ronaldo de Carvalho e Eduardo Guimarães, saindo o $1^{\circ}$ número no final de Março, o $2^{\circ} \mathrm{em}$ Junho, com quatro pinturas futuristas de Santa-Rita pintor, o $3^{\circ}$ permanecendo inédito, por falta de dinheiro, e só em 1953 é que Adolfo Casais Monteiro publicará alguns dos poemas e em 1984 a editora Ática o imprimirá por completo. Anos mais tarde, mais precisamente após 1925, Fernando Pessoa, ao elogiar o poema dramático Auto da Vida Eterna de Augusto Santa-Rita como a primeira obra 
literária portuguesa em que as doutrinas ocultistas entravam plenamente, nomeadamente a do corpo astral e a da sobrevivência da alma, assinalará mais expressamente que já na Orpheu circulava a corrente ocultista, embora na revista Exilio, de 1916, de Augusto de Santa Rita, na qual colaborou marcadamente, também o afirmasse numa espécie de Manifesto Sensacionista todo ele impregnado de esoterismo, com que fecha a revista.

$\mathrm{Na}$ verdade nesse mesmo ano de 1915 descobria com grande impacto a Teosofia, ao ter de traduzir alguns livros (virão a ser seis) que a Editora A. M. Teixeira, de Lisboa, Ihe encomendara, sendo talvez o agente de ligação João Antunes, director da colecção, e autor de estudos para a época bons sobre o Ocultismo e que era amigo de Raul Leal, colaborador da colecção e depois do Orpheu, embora a sua mestria do inglês e do seu interesse pelo Ocultismo fossem provavelmente conhecidos do pequeno meio literário e ocultista lisboeta.

Nessa época começara a praticar a escrita automática do espiritismo, tão em moda nos surrealistas franceses, com regularidade, em perguntas ora juvenis e afectivas ora em respostas em letra miudinha com conselhos mais espirituais. $O$ estudo das Astrologia também se desenvolve então fortemente e no fim da sua vida mais de 2.000 fragmentos do espólio dirão respeito a esta arte, na qual chegou mesmo a pensar profissionalizar-se tal era a sua crença no Destino e no influxo dos astros e do que eles simbolizam, e que ele tanto estudara e conhecia.

É nesta altura que lhe acontece a "alvorada" de faculdades suprassensoriais, bem descrita na famosa e extensa carta confessional à tia Anica, então em Paris, de 24 de Junho de 1916, onde realça os fenómenos de visão etérica, visão astral e telepatia anímica que vivencia ou com que é agraciado. Este despertar dos sentidos subtis e ocultos foi mais tarde meditado e teorizado no caminho iniciático, considerando-o mesmo como um degrau importante na conquista de conhecimento do lado interno e divino das coisas e seres.

Um dos diários, o de Novembro de 1915, assinala a recepção das provas da sua tradução dos Ideais da Teosofia, embora o primeiro a ser entregue seja o Compêndio de Teosofia, de C. Leadbeater, em Setembro. É também de Dezembro deste ano o nascimento do seu semi-heterónimo astrólogo, pagão e esoterista Rafael Baldaya, o qual tentará lançar um movimento de despertar pagão, ocultista e espiritual de Portugal, reagindo contra certos aspectos teosóficos, mas do qual restam apenas umas escassas páginas dos Princípios de Metafísica Esotérica, do Tratado da Negação e dos comentários às Trovas de Bandarra, além de escritos astrológicos. Esta reacção crítica à Teosofia, patente em vários textos, aparece no diário de 1916, a 7 de Dezembro, onde refere ter traduzido várias cartas, sentir-se sem depressão e ter tido "o começo de um pensamento claro, ocultisticamente anti-teosófico".

Anote-se que as cartas traduzidas referem-se ao que foi a principal profissão de Fernando Pessoa, tradutor ou correspondente estrangeiro em vários escritórios e casas comerciais (embora também se denominasse gerente para o estrangeiro), ambientes que afloram magistralmente na sua famosa "produção doentia", como chamou ao Livro do Desassossego que, apesar desse tom geral cinzento, ainda assim contém revelações da luz do espírito dissipando nuvens e depressões, tal como Bernardo Soares regista "não saber de si é viver. Saber mal de si é pensar. Saber de si, de repente, como neste momento lustral, é ter subitamente a noção da mónada íntima, da palavra mágica da alma". ${ }^{1}$

Na sua formação, para além das tendências ou inclinações inatas e dos livros lidos (muitos anotados, ou com parte transcritas, servindo para escritos), não sabemos bem a dimensão dos diálogos que teve com conhecedores do ocultismo e da espiritualidade, tal como Raúl Leal, Leonardo Coimbra, Teixeira Pascoaes, César Porto, Kamenesky, Augusto Ferreira Gomes, Augusto de Santa-Rita (que elogiou muito pelo seu Auto da Vida Eterna), Mário Saa, Manuel de Meneses e João Antunes (que, por exemplo, no seu Oedipo, a História e a Filosofia do Hermetismo, de

\footnotetext{
${ }^{1}$ Livro do Desassossego, por Bernardo Soares. Por Jacinto Prado Coelho, Alhiete Galhoz e Teresa Sobral Cunha. Vol.I., pag. 199. Lisboa, Ática, 1982.
} 
1917, nomeia Leonardo Coimbra e Teixeira Rego), Almada Negreiros, e com os quais terá eventualmente dialogado sobre aspectos dos seus estudos da Tradição Ocultista ou Hermética. Contudo, é só e para a sua Arca de madeira que vai redigindo milhares de poemas e textos, sob vários títulos, alguns deles atingindo várias páginas autonomizáveis em conjuntos, como a alguns veio a acontecer postumamente, talvez sem o rigor e a compreensão contextualizante que exigiriam para serem mais fiéis à intencionalidade e à demanda do próprio Fernando Pessoa.

De facto quem trabalha, por exemplo, nos fragmentos inéditos ou menos conhecidos, e os publica, enfrenta ou atravessa algumas questões, desde a decifração e fixação do texto à sua publicação e inclusão sob um título ou num livro. $\mathrm{O}$ conceito de obra aberta está então plenamente vivo quando estudamos ou lemos Fernando Pessoa, obrigando-nos a uma cuidadosa contextualização e comparação antes de se dar a interpretação ou a inclusão final num título ou num contexto, certamente sempre melhorável, tal como temos visto nas sucessivas edições do Livro do Desassossego.

Por exemplo, no meu caso, após a investigação nas pastas do Espólio depositado na Biblioteca Nacional, onde se encontram os cerca de 25.000 papéis dele, autonomizei quatro livros, dois com títulos de Fernando Pessoa, o Moral, Regras de Vida, Condições de Iniciação, e o Rosea Cruz, sendo os textos escolhidos e ordenados por mim. $\mathrm{Na}$ Poesia Profética, Magica e Espiritual incluí poemas inéditos e alguns éditos sobre esses temas, apercebendo-me das suas ligações com textos de ensinamentos iniciáticos ou ocultistas que nos deixou. $\mathrm{Na}$ Grande Alma Portuguesa publiquei a carta ao conde de Keyserling, sobre os três níveis dela e os seus movimentos principais no tempo, contextualizando-a com alguns textos inéditos sobre Portugal e comentando-a amplamente, com frequentes citações de Fernando Pessoa.

Neste sentido, cada estudioso ou especialista transmite a sua própria visão do que sente ou intui ser a correcta inserção de textos sob um título possível, projecto inacabado ou doutrina, e deveremos evitar dar títulos a textos que não os tem e menos ainda despropositadamente. Deveríamos ter muito bem claro e presente o que Fernando Pessoa pensava e queria pessoalmente e com o rigor que por várias vezes transmitiu: o dever de se dar o melhor ou mais verdadeiramente possível à obra, como missão divina, resumindo ele tal caminhar na vida iniciaticamente na regra e lema Talent de Bien Faire, que the vinha do Infante D. Henrique...

Como exemplos de títulos ao alto das páginas, em geral manuscritas, na vertente ocultista ou hermética, encontramos Ocultismo, Hermetic Philosopher, Subsolo, 300, Rosacruz, Way of the Serpent, Essay on Initiation (dos mais interessantes, com bastantes páginas sobre o desenvolvimento da intuição e da genialidade), FM, Jews and FM, FM, Ordem de Cristo de Portugal, Ordem Templária de Portugal, Chrisalida, Phoenix, Átrio, Rosicrucians, R. C. Initiation, etc.

Se observarmos mais cuidadosamente este espólio ocultista de Fernando Pessoa notamos vários textos ligados com as ordens iniciáticas, os seus graus ou escalas e as tabelas de correspondências variadas, tais como as Sefirotes da Cabala, os Anjos, os nomes de Deus, os números, mostrando nisso alguma propensão matemática e numerológica, certamente afim dos seus mais de 2.000 papéis sobre Astrologia. Noutros já se encaminha mais para as qualidades desenvolvidas, das quais se destaca a sensibilidade aos símbolos, a intuição e depois a inteligência da intuição e estão ligadas tanto ao ocultismo como ao génio criador literário.

A análise e a meditação da Maçonaria e da simbologia associada a ela ocupa bastante da sua produção ocultista e vemo-la não só nos textos escritos sob os títulos Maçonaria, Jews and FM, M.G. (Grau de Mestre), ou ainda nos da polémica do último ano da sua vida acerca da proposta do deputado José Cabral de uma Lei contra a Liberdade das Associações Secretas, como também em estudos acerca dos comentários de Oswald Wirth a um desenho da obra maçónica de Jean Marie Ragon, ou ainda nos estudos e recriações dos símbolos dos 
Rosacrucianos e Templários que por alguns modos ou transmissões teriam chegado até à Maçonaria com uma sabedoria e um potencial iniciático, isto é de despertarem uma intensificação anímica, um discernimento e uma maior aspiração à luz, como afirmará

Com efeito, os estudos e ensinamentos relativos aos simbólicos mestres Hiram, Christian Rosenkreutz, Jean Jacques de Molay, D. Sebastião e Jesus são frequentes, tal como também a outro nível, talvez mais proveniente do seu gosto pelo misterioso e o policial, os das relações e lutas entre Maçonaria, os Rosicrucianos, o Concílio Pagão, a Ordem dos 300 , os Mestres da Doutrina Secreta e das Altas Ordens, por vezes com um carácter algo mistificante ou mitificante, como é o caso dos 300 , dos "Déspotas do Concílio Pagão" e dos "Mestres da Ordem do Encoberto" estes últimos congregando-se para uma "animação do espírito árabe", pagão.

Há especulações tanto sobre a matriz judaicocristã, nomeadamente o Genesis, acerca da criação do mundo e a queda dos Anjos e do Homem, frequentemente exploradas com recurso à simbologia da Gnose, da Cabala, da Astrologia, do Hermetismo, como também, embora mais lateralmente, referências à tradição celta e árabe e sobretudo à matriz grecoromana pagã e em especial os ensinamentos dos Mistérios, como por exemplo quando nos diz: "O certo é que os ensinamentos ministrados nos Mistérios abrangem três ordens de coisas: (1) a verdadeira natureza da alma humana, da vida e da morte, (2) a verdadeira maneira de entrar em contacto com as forças secretas da natureza e manipulá-las, e (3) a verdadeira natureza de Deus ou dos Deuses e da criação do mundo. São, respectivamente, o segredo alquímico, o segredo mágico, e o segredo místico. Ao primeiro chama-se alquímico porque os ensinamentos relativos a ele são em geral ministrados através de símbolos da chamada alquimia, que não é mais, como hoje claramente se sabe, do que uma linguagem simbólica..." (BNP/E3, 54-97).

Considerando os símbolos como a linguagem mais apropriada à transmissão dos ensinamentos esotéricos ou espirituais em vários textos nomeará ou caracterizará sumariamente os cinco (em geral, embora por vezes 7 ou 10) níveis ou sentidos interpretativos ou de hermenêutica: moral, histórico, filosófico, religioso e místico. Ou noutra versão: literal, alegórico, moral, espiritual e divino. Ou ainda: profano, moral, filosófico, espiritual, angélico e divino. Daí a sua afirmação de que a conversa com o anjo da Guarda era a mais alta obra de Magia e a procura de uma ligação a Deus ou a Cristo, bem patente em alguns poemas mais devocionais juvenis e noutros posteriores.

Há ainda algumas referências à Índia e aos seus sistemas e ensinamentos, embora fragmentárias, pouco aprofundantes e por via sobretudo da Teosofia e de alguns livros orientalistas, ou até das Confissões de Aleister Crowley, excepto duas ou três de forte que de facto tem um grande valor vertical de iluminação, como por exemplo: "No ocultismo dos Índios o Mestre, a quem os discípulos procuram, é a própria substância monádica do discípulo. "Eu próprio sou o cantor", diz-se no poema sagrado [Bhagavad-Gita]. "Só há a procurar o que já se encontrou." (BNP/E3, 24-75).

As críticas à Teosofia e ao Budismo esotérico, tal como este era transmitido por ela, foram fortes, ainda que em certos textos ou poemas anteriores haja belas e criativas páginas sobre Sakya Muni e o Nirvana, e noutros textos posteriores as venha a amenizar, reconhecendo o valor da Teosofia em certos aspectos, nomeadamente na divulgação de ensinamentos dos Mistérios antigos e do Ocultismo, algo que nos seus primeiros anos de juventude ele criticava, dentro de uma perspectiva algo demasiado aristocrática, anti-humanitarista, anti-femininista e anti-Oriental que o caracterizava.

Já as críticas à Maçonaria juvenis deram lugar a um estudo muito intenso, podendo dizer-se que na sua época seria um dos seus maiores conhecedores, tal como ele próprio o afirma, o que uns meses antes da sua morte o fez sair a público em defesa dela (a 4/2/1935, a pedido de Norberto Lopes, então "subdirector" do Diário de Lisboa), já que estava a ser posta em causa no tal projecto de Lei contra as Associações Secretas e, provavelmente, a redigir o 
seu testamento ou nota autobiográfica afirmando mais veementemente a sua afinidade com a Gnose, a Cabala, a Maçonaria, o Cristianismo Esotérico ou Gnóstico, os Templários.

Este último ano da sua vida é intenso e dramático e apenas podemos imaginar o que se passaria dentro dele quando se foi apercebendo que a ditadura salazarista começava a funcionar ao impor censura ao que se escrevia, tal como ouviu no discurso de Salazar na atribuição dos prémios Literários do Secretariado de Propaganda Nacional, onde não foi embora tivesse recebido o prémio Antero de Quental pela Mensagem, a qual seria depois apregoada por alguns como obra de profecia ou defesa do regime do Estado Novo, o que não the agradou muito e que passou a ser fonte de vários poemas críticos ou trocistas.

Num texto não publicado desse último ano da sua vida, e escrito a propósito da opressão às sociedades secretas que o Estado Novo de Salazar começara, Fernando Pessoa caracterizou-se politicamente, numa síntese muito concentrada de espiritualidade e política, já que funda a sua identificação de Liberal na origem Divina da alma:

"Fui sempre, e através de quantas flutuações houvesse, por hesitação de inteligência crítica, em meu espírito, nacionalista e liberal: nacionalista - quer dizer, crente no País como alma e não como simples nação; e liberal - quer dizer, crente na existência, de origem divina, da alma humana, e da inviolabilidade da sua consciência, em si mesma e em suas manifestações. Por isso me foram sempre origem de repugnância e asco todas as formas do internacionalismo, que são três: a Igreja de Roma, a finança internacional e o comunismo." (BNP/E3, 138A-57r).

Quanto ao Cristianismo, e Jesus e Maria, ou nas suas doutrinas, vemos múltiplas "avatarizações", isto é, apreciações sobre o que de Divino ou de Verdade desceria ou se manifestava neles e, nessa época em que o culto a Nossa Senhora de Fátima era erguido como o do altar máximo do nacionalismo católico, Fernando Pessoa entrou em claro confronto com a instituição, sobretudo de Roma, tanto mais que sentia que a Igreja estaria também apoiando a lei contra as Associações Secretas, ou seja, contra a Maçonaria e por extensão implícita às Ordens Iniciáticas e à Liberdade do Pensamento...

Daí provavelmente na sua nota autobiográfica final a crítica forte à Igreja de Roma ("Cristão gnóstico e portanto inteiramente oposto a todas as Igrejas organizadas, e sobretudo à Igreja de Roma", bem como alguns dos seus projectos editoriais de 1935 dirigidos em parte contra ela e intitulados: Tarde e Más horas (em defesa das Associações Secretas), Marcha de Roma, Fátima e Praça da Figueira, este o que continha os poemas algo brincalhões ou irónicos em relação aos três santos populares dos portugueses, e que só postumamente nos anos noventa foram publicados.

Com que ligações espirituais e religiosas Fernando Pessoa entrou no além (ou pelo menos saiu da vida terrena...) poder-se-á de algum modo deduzir-se, pois afirma-se Cristão Gnóstico, crente na divindade de Cristo e, em poemas finais, no papel misericordioso de Maria, Mãe Divina (em intersecionismo com a saudade grande da mãe humana, que transparece no longo poema Un soir au Lima, escrito dois meses antes de morrer) e crente também na orientação dos mestres e anjos. Nestes três tipos de seres intermediários com o Ser Divino confluem vários textos e poemas dos últimos tempos da sua existência terrena ou corporal, além da sua carta a Adolfo Casais Monteiro, de Janeiro de 1935: "Creio na existência de mundos superiores ao nosso e de habitantes desses mundos, em experiências de diversos graus de espiritualidade, subtilizando até se chegar a um Ente Supremo, que presumivelmente criou este mundo"

Além desta sua escolha do Cristianismo Gnóstico como alinhamento religioso, haverá que reafirmar a sua tentativa de ressurgência da Ordem de Cristo ou Templária de Portugal, em consonância com o que afirma no seu testamento ou nota autobiográfica de 30 de Março de 1935: "Posição iniciática: Iniciado, por comunicação directa de Mestre a Discípulo, nos três graus menores da (aparentemente extinta) Ordem Templária de 
Portugal".

E deixa-nos ao finalizar tal nota o seu testamento de cidadania espiritual: "Ter sempre na memória o mártir Jacques de Molay, grão-mestre dos Templários, e combater, sempre e em toda a parte, os seus três assassinos - a Ignorância, o Fanatismo e a Tirania".

Para concluir esta breve hermenêutica da sua vida e obra iniciática ouçamos talvez um dos seus ensinamentos mais profundos (no espaço anímico) e último (no tempo corporal), muito provavelmente escrito no último ano ou meses de vida:

"O conhecimento de Deus não depende do hebreu, nem de anagramas, nem de símbolos, nem de língua alguma, falada ou pensada; faz-se pela ascensão univocal da alma, pelo encontro final da alma consigo mesma, do Deus em nós consigo mesmo." (BNP/E3, 53 B-20.)

\section{Referências}

MOTA, Pedro T. da. Moral, Regras de Vida e Condições de Iniciação. Lisboa: Edições Manuel Lencastre, 1988.

MOTA, Pedro T. da. A Grande Alma Portuguesa. Lisboa: Edições Manuel Lencastre, 1988.

MOTA, Pedro T. da. A Rósea Cruz. Lisboa: Edições Manuel Lencastre, 1989.

MOTA, Pedro T. da. Poesia Profética, Mágica e Espiritual. Lisboa: Edições Manuel Lencastre, 1989. 